\title{
Mineração
}

\section{Estabilidade dos taludes da Cava Cachorro Bravo com base em modelagem numérica por elementos finitos}

\section{(Sope stability of Cachorro Bravo open pit through numerical modeling by finite element method)}

\author{
Carolina Helena Caldeira Silva \\ Mestranda,PPGEM,DEMIN, UFOP.E-mail:carolcaldeiras@uai.com.br \\ Milene Sabino Lana \\ Professor Adjunto, DEMIN, UFOP. E-mail:milene@demin.ufop.br \\ Luana Cláudia Pereira \\ Graduando, Engenharia Ambiental, UFOP.E-mail:Icpamb@yahoo.com.br \\ Manoel da Conceição Lopes \\ Mestre,PPGEM, DEMIN, UFOP.E-mail:manoellopes@uai.com.br
}

\begin{abstract}
Resumo
Esse trabalho apresenta a análise da estabilidade de um talude da Mina Córrego do Sítio, que pertence ao Grupo Anglo Gold Ashanti, e encontra-se inserida na porção nordeste do Quadrilátero Ferrífero. No local, ocorrem rochas metamórficas deformadas, com significativas descontinuidades que ocasionam problemas geotécnicos. Os objetivos do estudo foram analisar os fenômenos de ruptura observados na Cava Cachorro Bravo, em 2003, e avaliar a estabilidade dos taludes da cava, em 2006, a partir da simulação da evolução da lavra nesse período. Para tal, utilizou-se um modelo computacional, por meio do software Phase 26.0 da Rocsciense (Canadá), que permite a modelagem do maciço através do método dos elementos finitos. Os resultados mostraram-se satisfatórios, reproduzindo a situação observada em campo e indicando a necessidade de novos estudos para avaliação da estabilidade dos taludes a longo prazo.
\end{abstract}

Palavras-chave: Mecanismos de ruptura, flambagem, alteração, estabilidade de taludes.

\begin{abstract}
This work presents a slope stability analysis in Córrego do Sitio mine, that belongs to Anglo Gold Ashanti Group. The mine is situated in the northwestern portion of the Quadrilatero Ferrifero. Deformed metamorfic rocks and significant discontinuities occur in this place, leading to geomechanical problems. The objectives of this study were to analyze failure mechanisms that occurred in the Cachorro Bravo open pit in 2003, and to evaluate the pit stability in 2006, by simulating the mining excavation effects along this period. The software Phase 26.0 of Rocsciense (Canada), which models the rock mass using the finite element method, was used. The results were satisfactory, reproducing the situation observed in the field and indicating the need for new studies to evaluate the long term slope stability.
\end{abstract}

Keywords: Failure mechanisms, buckling, weathering, slope stability. 


\section{Introdução}

No Quadrilátero Ferrífero, estudos de estabilidade de taludes em filitos são de grande relevância, já que essas rochas metamórficas se encontram deformadas, com descontinuidades estruturais que determinam importantes mecanismos de ruptura, além de grau de alteração acentuado, fatores que ocasionam diversos problemas geotécnicos.

Alguns estudos evolvendo análises de estabilidade de taludes em filitos têm sido realizados na região do Quadrilátero Ferrífero; destacam-se: Lopes (2006), Figueiredo e Aquino (2005), Ferreira (2004), Pinheiro (2002), Fernandes (2000).

Nesse trabalho, foi abordado o estudo de mecanismos de ruptura de um talude em filito na Cava Cachorro Bravo, Mina Córrego do Sítio, do Grupo Anglo Gold Ashanti, situada a aproximadamente $20 \mathrm{~km}$ do município de Santa BárbaraMG, cujas cavas são constituídas por frentes de lavra de minério oxidado de ouro

As rochas em estudo constituemse de filitos associados a metagrauvaca, intercalados por diques de rocha básica. A ocorrência de dobramentos, fraturamento acentuado em algumas áreas, e o clima tropical úmido conduziram à formação de rochas de baixa resistência mecânica.

Foram realizadas análises de tensão-deformação do talude. O programa Phase $^{2}$, versão 6.0, da Rocscience, baseado no método dos elementos finitos, foi empregado nas análises.

Numa primeira situação, foi utilizada uma seção da Cava Cachorro Bravo, correspondente ao talude escavado em 2003. O objetivo dessa análise foi avaliar a importância relativa dos diversos parâmetros de entrada do modelo e realizar retroanálises desses parâmetros, com base na ruptura ocorrida na época.

Numa segunda situação, foi utilizado um perfil mais atual (2006), resultante da escavação da rocha, para retirada do minério de interesse. A estabilidade dos taludes a longo prazo foi avaliada; os dados de resistência utilizados levaram em consideração a alterabilidade da rocha.

\section{Mecanismos de ruptura na Cava Cachorro Bravo}

Em julho de 2003, ocorreu uma ruptura por flambagem ("buckling") ao longo da superfície de foliação, próximo ao pé de um talude na Cava Cachorro Bravo, ver Figura 1. Esse fenômeno ocorreu em nível de bancada.

O fenômeno de flambagem ocorre quando as descontinuidades mergulham no sentido da face do talude, com um mergulho maior que o mergulho da face. Essas condições estavam presentes para a superfície de foliação nos taludes de bancada na Cava Cachorro Bravo.

Também foi observada, na época, uma ruptura de razoáveis proporções em Cachorro Bravo, envolvendo vários bancos, como mostra a Figura 2.

\subsection{Modelagem numérica dos mecanismos de ruptura}

Nesse estudo, foi utilizado o método de elementos finitos, através do programa Phase 6.0 , da Rocsciense (Canadá).

$\mathrm{Na}$ seção fornecida pela empresa com a geometria do modelo, foram inseridas, manualmente, as descontinuidades de foliação, com mergulho de $61^{\circ} \mathrm{e}$ direção paralela à face do talude, correspondente à sua atitude média. O objetivo era reproduzir, o mais fielmente possível, o mecanismo de ruptura por flambagem, cujo deslocamento total aproximado observado em campo foi de $0,4 \mathrm{~m}$ na placa onde ocorreu a flambagem (Figura 1).

\section{Resultados e discussão}

O estudo de estabilidade foi realizado para duas situações distintas envolvendo um talude da Cava Cachorro Bravo. Na primeira, foi utilizada uma seção que corresponde à geometria da cava em 2003 (Figura 3), como citado anteriormente. Na segunda situação, foi utiliza-

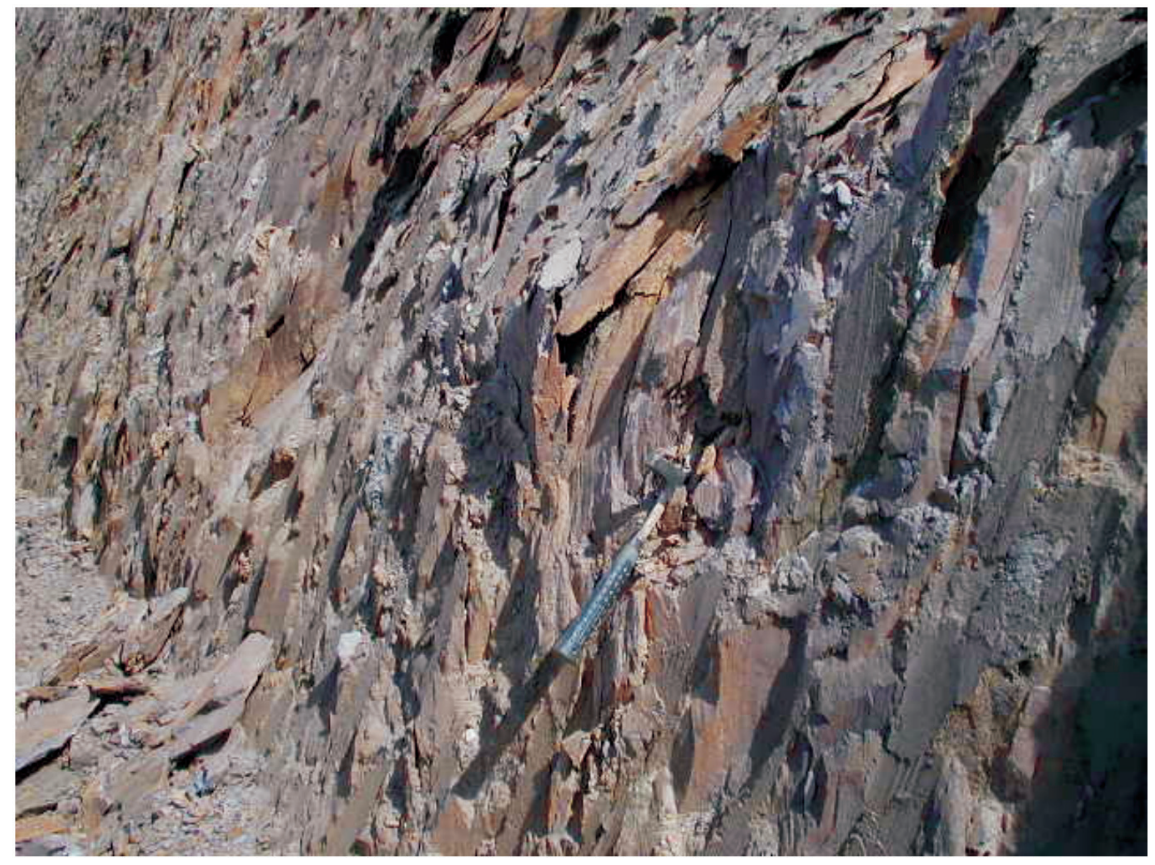

Figura 1 - Ruptura por flambagem em talude da Cava Cachorro Bravo. 
do um perfil mais atual (2006), resultante da escavação da rocha em direção à cava final.

O carregamento utilizado foi devido a um campo inicial de tensões gravitacionais, variando-se o valor das tensões horizontais, até que fosse obtido um bom ajuste com os valores de deslocamento observado em campo, ou seja, de $0,4 \mathrm{~m}$ na placa onde ocorreu a flambagem. Isto ocorreu para tensões horizontais médias 1,5 vezes maiores que as tensões verticais.

As dimensões da malha gerada no modelo seguiram, inicialmente, as recomendações de Sjöberg (1999), ou seja, o modelo foi estendido em 2 vezes a altura total do talude e 4 vezes a largura. Posteriormente, a partir dos resultados da simulação, verificou-se a necessidade de expandir as dimensões da malha; a altura passou a ser em torno de 8 vezes a altura total do talude e a largura se manteve.

O modelo constitutivo elasto-plástico de Mohr-Coulomb foi utilizado para a resistência dos materiais, no caso filitos com intercalações de rocha básica (Figura 3). As propriedades mecânicas e os parâmetros de deformabilidade utilizados na modelagem, como ponto de partida para as análises, foram obtidos de relatórios internos da empresa, dados de laboratório e literatura técnica (Hoek \& Brown, 1997; Hoek et. al., 2002; Figueiredo \& Aquino, 2005). Esses parâmetros sofreram ajustes durante a modelagem para melhor representar a situação de campo, em termos de deslocamentos.

Na segunda situação simulada, correspondente à geometria da cava em 2006, foram utilizados parâmetros de resistência de filitos alterados, obtidos através da realização de ensaios de ciclagem (Lopes, 2006), no intuito de analisar o comportamento do talude mediante a atuação de processos intempéri$\cos$, visando à simulação da estabilidade a longo prazo dos taludes finais de cava.

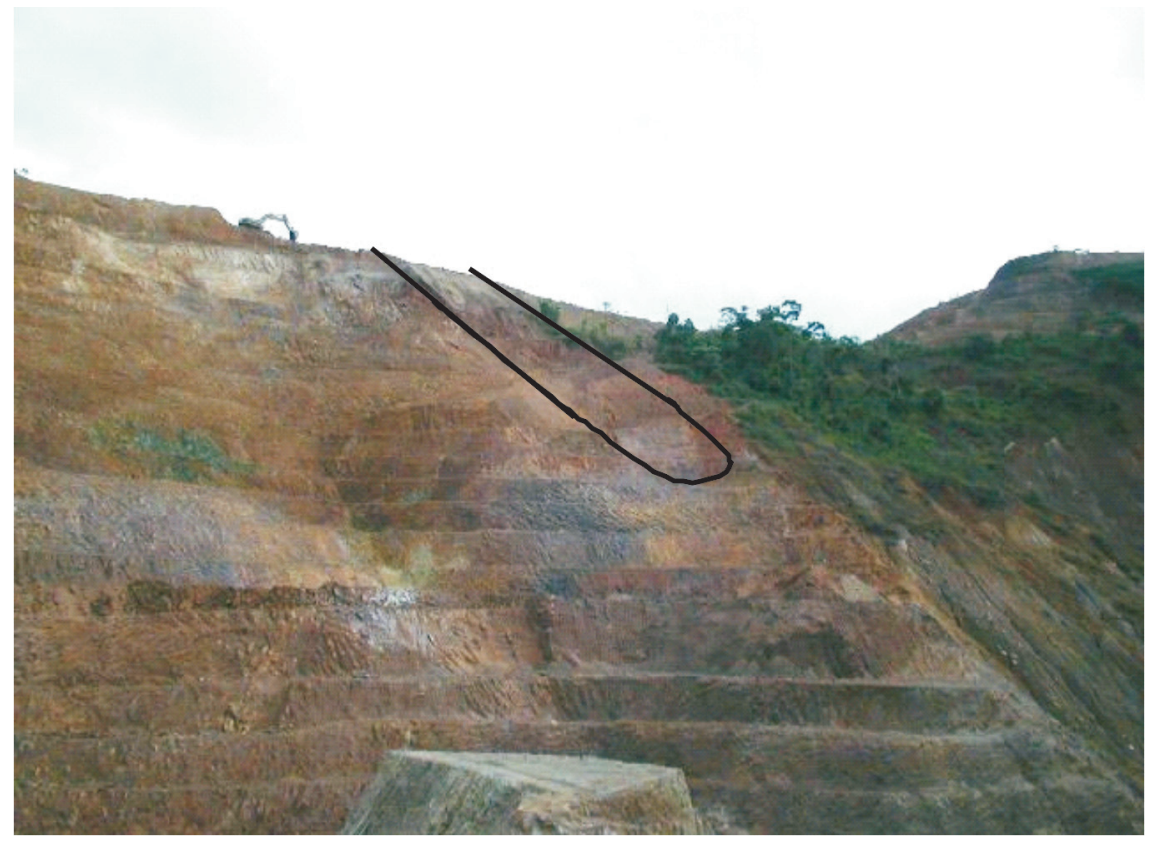

Figura 2 - Ruptura ocorrida na Cava Cachorro Bravo, envolvendo vários bancos.

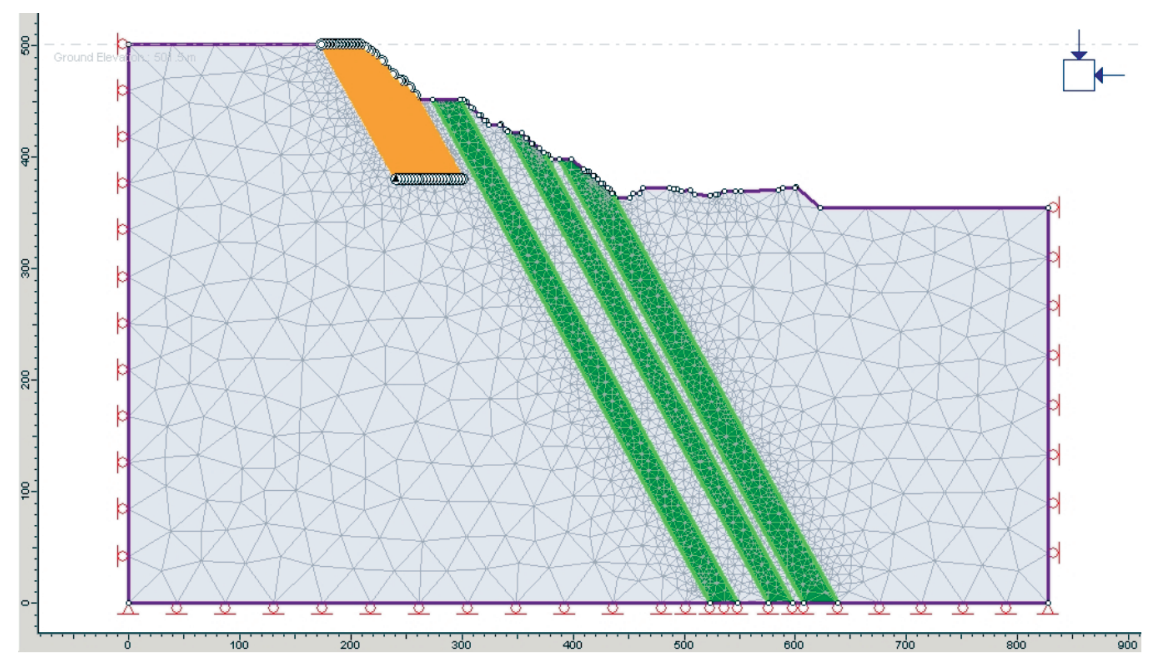

Figura 3 - Modelo computacional para a análise.

Os valores de coesão e ângulo de atrito, mostrados na Tabela 1 , foram utilizados como dados de entrada para o filito.

Os resultados da simulação, para a primeira situação, são apresentados na Figura 4. Observa-se um deslocamento total em torno de $0,4 \mathrm{~m}$, como observado em campo. A superfície de ruptura encontrada na análise é relativamente próxima da superfície global de ruptura, maTabela 1 - Parâmetros de entrada (c e $\phi)$.

\begin{tabular}{c|c|c}
\hline Filito & $\mathbf{c}(\mathbf{k P a})$ & $\boldsymbol{\phi}{\left({ }^{\circ}\right)}^{\circ}$ \\
\hline Situação 1 & 158,94 & 33,77 \\
\hline Situação 2 & 118,26 & 32,90 \\
\hline
\end{tabular}
peada em campo. A ruptura por flamba- 
gem foi verificada como sendo um modo de ruptura local, na área em estudo, ocorrendo em nível de bancada (altura de $6 \mathrm{~m}$ e berma de $3 \mathrm{~m}$ ), havendo separação das placas rochosas, como pode ser observado na Figura 1. Ainda no que diz respeito a esta ruptura, verifica-se, pela Figura 5, uma alta concentração de pontos de tração na região em que ocorreu a ruptura, o que pode ser corroborado em campo pela presença de significativas fendas de tração próximas às cristas dos bancos.

Simulando-se uma situação de cava final (seção de 2006) e utilizando-se os parâmetros da rocha alterada (c e $\phi)$, pode-se observar que a ruptura é bem maior, apresentando um deslocamento total de 3,6 m, como pode ser visto nas Figuras 6 e 7. Na modelagem dessa situação, verificou-se que não houve convergência dos deslocamentos, situação de visível colapso global do talude. Isso foi considerado como uma indicação de que a estabilidade do talude a longo prazo vai diminuir consideravelmente e rupturas de grandes dimensões poderão ocorrer.

\section{Considerações finais}

As análises de estabilidade de taludes na região do Quadrilátero Ferrífero são importantes, devido aos inúmeros problemas geotécnicos encontrados nessa área. A análise da ruptura ocorrida na Cava Cachorro Bravo permitiu razoável compreensão do comportamento do maciço frente ao mecanismo de ruptura, por ora de forma preliminar, podendo servir de ponto de partida para estudos mais aprofundados sobre o mecanismo de ruptura em Cachorro Bravo e em outras áreas da mina que apresentem padrões semelhantes. Os resultados encontrados, através da utilização do software Phases 2 6.0, mostraram-se satisfatórios, uma vez que reproduziram as condições verificadas em campo, na época da ruptura em 2003. Os resultados obtidos, para a situação da cava em 2006, evidenciaram indícios de ocorrência futura de rupturas de grandes dimensões, que devem

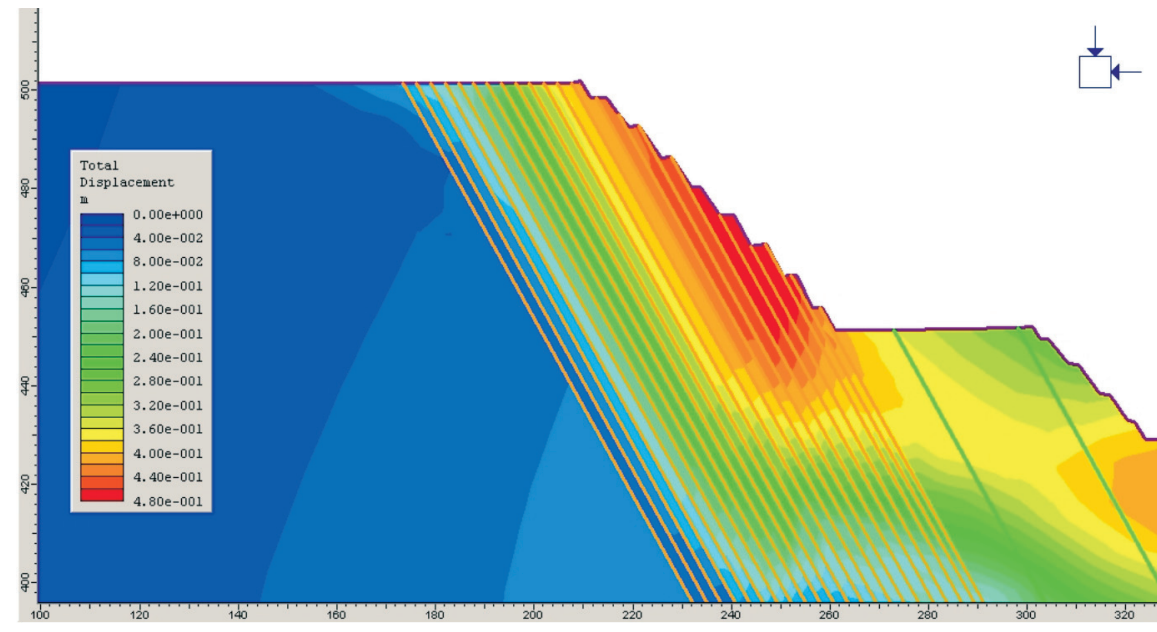

Figura 4 - Deslocamento total em 2003.

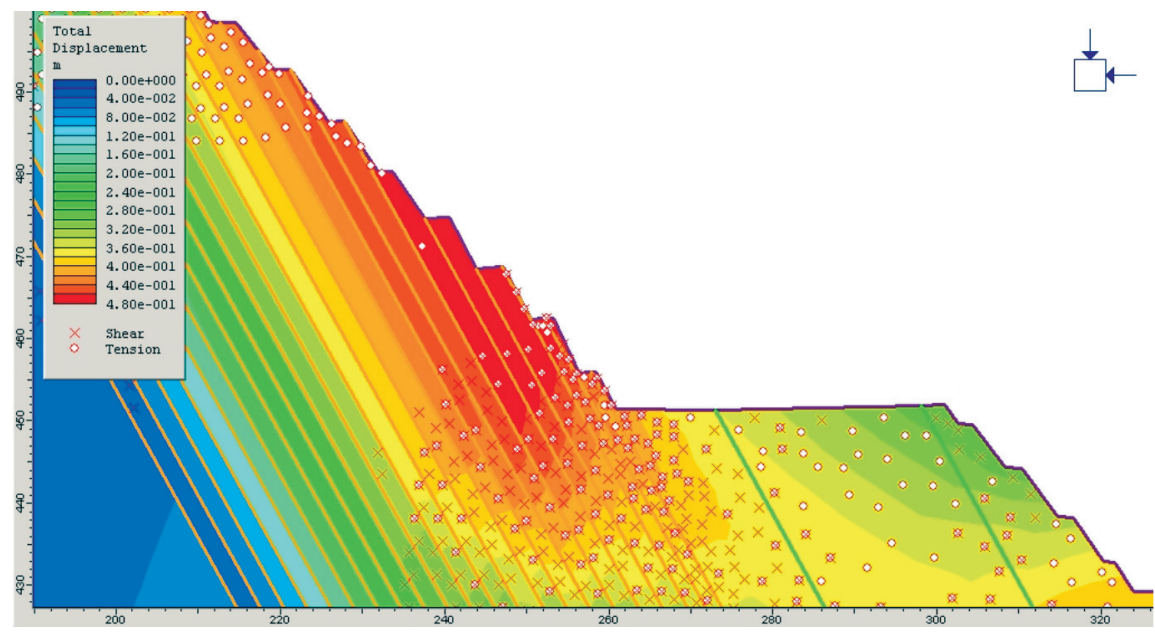

Figura 5 - Região de tracionamento.

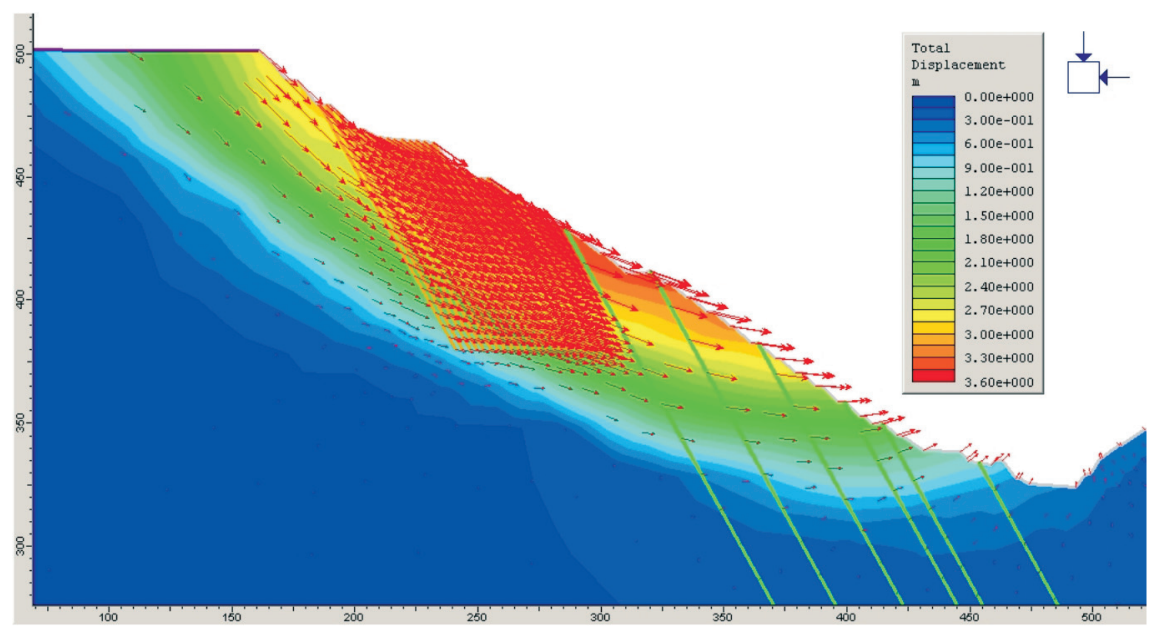

Figura 6 - Possível superfície de ruptura para simulação de cava final. 
ser verificadas por estudos mais aprofundados, a partir da introdução de parâmetros de entrada mais precisos na modelagem numérica.

\section{Referências bibliográficas}

FERNANDES, G. Caracterização geológicogeotécnica e proposta de estabilização da encosta do Morro do Curral. Centro de Artes e Convenções de Ouro Preto. Ouro Preto: Universidade Federal de Ouro Preto, 2000. 136p. (Dissertação de Mestrado).

FERREIRA, S. B. Estudo de ruptura em talude urbano no Morro do Curral, Ouro Preto. Ouro Preto: Universidade Federal de Ouro Preto, 2004. 87p. (Dissertação de Mestrado).

FIGUEIREDO, R.P., AQUINO, T.V.C. Caracterização e retro-análise preliminar do mecanismo de tombamento flexuralMina do Pico/MBR. In: CONGRESSO BRASILEIRO DE GEOLOGIA DE ENGENHARIA E AMBIENTAL, 11. Anais... Florianópolis: Associação Brasileira de Geologia de Engenharia e Ambiental, 2005. p. 2274-2290.

HOEK, E., BROWN, E. T. Practical estimates of rock mass strength. Intnl.

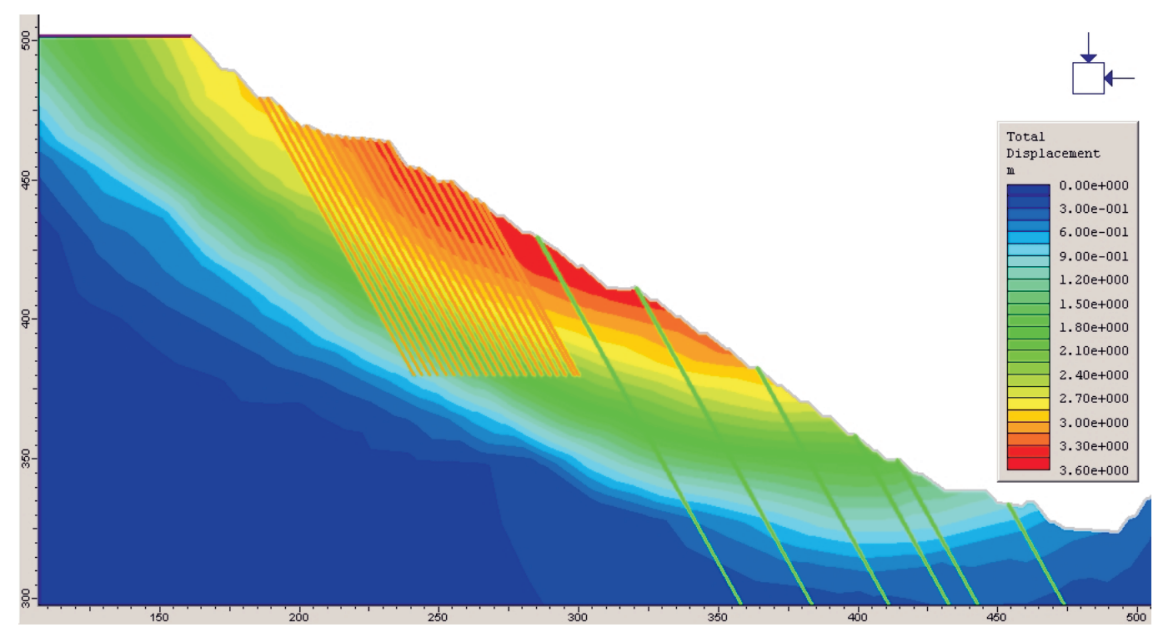

Figura 7 - Deslocamento total da seção escavada.

J. Rock Mech. and Minig. Sci. \& Geomechanics Abstracts, v.34, n. 8, p.1165-1186, 1997.

HOEK, E., CARRANZA-TORRES C., CORKUM, B. Hoek-Brown failure criterion-2002, www.rocscience.com, 7p. 2002.

LOPES, M. C. Comportamento geotécnico e mecanismos de ruptura em rochas brandas Mina Córrego do Sítio. Ouro Preto: Universidade Federal de Ouro Preto, 2006. 94p. (Dissertação de Mestrado).

PINHEIRO, A. L. Análise de rupturas em taludes do Morro do Curral, Ouro Preto, Minas Gerais. Ouro Preto: Universidade Federal de Ouro Preto, 2002. 116p. (Dissertação de Mestrado).

SJÖBERG, J. Analysis of large scale rock slopes. Lulea, Sweden: Lulea University of Technology, 1999. 788p. (Doctoral Thesis).

Artigo recebido em 27/06/2007 e aprovado em 01/03/2008. 